\title{
sciendo
}

\section{Does Youth Soccer Players' Group Cooperation Improve when Pitch, Goal, and Team Size Are Reduced?}

\author{
by \\ Antonio García-Angulo, ${ }^{1,2}$ Enrique Ortega-Toro ${ }^{1,2}$, José María Giménez-Egido, ${ }^{1,2}$ \\ Aurelio Olmedilla ${ }^{3}$, Alexandre García-Mas, José Manuel Palao ${ }^{5}$
}

The aim of this study was to analyse the effects of the modification of the pitch size, goal size, and the number of players per team on the level of cooperation in youth soccer players (U-12). A quasi-experimental design was implemented to measure the effects of the changes in the number of players per team (8-a-side vs. 5-a-side), goal size (6 $x 2 \mathrm{~m}$ vs. $3 \times 2 \mathrm{~m}$ ), and field size $(58 \times 38 \mathrm{~m}$ vs. $38 \times 20 \mathrm{~m})$ on the cooperation. Four soccer teams under-12 $(n=48$ players) participated in three tournaments (standard rules; proposed rules; standard rules). The five variables of cooperation were measured using the "Sports Cooperation Questionnaire": conditional cooperation, cooperation with the coach, disposition of unconditional cooperation, situational cooperation with teammates, and situational cooperation outside the field of play. Players presented the same level of cooperation in conditional cooperation, situational cooperation with teammates, and situational cooperation outside the field of play with both types of rules. The modification of rules involved a reduction of the cooperation with the coach and a disposition of unconditional cooperation. The causes of the reduction may be related to players' adaptation to new tactical dispositions and game situations. Future studies are needed of player's cooperation and different competition rules in youth sports.

Key words: : sport, teamwork, rules modification, sports initiation, adaptation.

\section{Introduction}

A positive dynamic group is important in an educational-sport environment (Moon, 2009; Scott-Ladd and Chan, 2008). Group Cooperation (GC) is a psychological factor related to the creation of a positive dynamic group and a behavioural indicator of a pro-social attitude (García-Mas et al., 2009; Olmedilla et al., 2011). GC is understood as a decisional process of basic coordination among a given group of people to associate, collaborate and achieve individual and common objectives. The development of GC is a fundamental part of teamwork in team sports (McEwan et al., 2018). Previous research has shown the importance of cooperation in the formative stages since it is an indicator that influences sports participation, adherence to practice and the development of emotional development strategies (Pons et al., 2016).

A positive enhancement that involves adapting competitive environments by changing the equipment, playing space, rules and roles in youth sports is supported by experience to competitive engineering (Burton et al., 2011; Giménez-Egido et al., 2020), sport system redesign (McCarthy et al., 2016), nonlinear pedagogy (Renshaw et al., 2012) and constraintled approach (Buszard et al., 2016). Analysing the

\footnotetext{
1 - Department of Physical Activity and Sport, Faculty of Sport Science, University of Murcia, Regional Campus of International Excellence "Campus Mare Nostrum", Murcia, Spain.

2 - Sport Performance Analysis Association, Murcia, Spain.

3 - Department of Personality, Evaluation and Psychological Treatment, Faculty of Psychology, University of Murcia, Murcia, Spain.

4 - Department of Basic Psychology, Faculty of Psychology, University of the Balearic Islands (UIB), Palma de Mallorca, Spain.

5 - Department of Health, Exercise Science and Sport Management, University of Wisconsin-Parkside, Wisconsin, USA.
} 
relationship between the modified competition rules and psychological variables, different authors point out the great advantages of adapting sport to children from the perspective of motivation (Balaguer et al., 2008; Duda, 1996), satisfaction (García-Angulo et al., 2017; Ortega et al., 2009), adherence (Farrow and Reid, 2010; Timmerman et al., 2015), self-efficacy (Chase et al., 1994; García-Angulo et al., 2020), friendship among peers (Mccalpin et al., 2017; Thomas and Wilson, 2015) and external relationships (Elliott et al., 2019). However, there are no studies that analyze the relationship between the use of modified competition rules and specific GC in youth sports (Almeida et al., 2013; Buszard et al., 2016; Lameiras et al., 2014).

The causes of cooperating in groups may be different, such as greater cost-effectiveness of cooperating against not cooperating (Chater et al., 2008), existence of a social norm in which such cooperation is expected and to which they adhere (Fehr and Gintis, 2007) or reciprocity. The perceived control and the risk are determining factors in the appearance of cooperation (Yang et al., 2013). Studies show that there are individual predictors in each of the members of the group that favours group cooperation, such as sportsmanship, moral competence or emotional intelligence, the latter being the most relevant factor in cooperation in events that have no future consequences, which reveals that cooperation is affected by emotional factors (Perry and Clough, 2017). A model to understand group cooperation in the field of physical activity and sport is the "Sports Cooperation model" (García-Mas et al., 2006).

According to this model, group cooperation is based on the player's personal decision to cooperate with the common group objective and has a combination of dispositional (cooperative tendencies) and situational factors (García-Mas et al., 2006). Group cooperation involves different factors, such as conditional cooperation, situational cooperation with the coach, disposition to unconditional cooperation, situational cooperation with teammates, and situational cooperation outside the field of play (García-Mas et al., 2006). The disposition for cooperation is related to the characteristics of a player and how they cooperate with their teammates and coaches to achieve a common goal. The situational cooperation is related to willingness to cooperate in different situations that occur during the game or outside it. Little is known about the effect of sports rules modification on cooperation. Research shows that a reduction of the number of players of the team involves an increase in sports cohesion, through increased interaction between players and through the simplest expression of their roles (Carron and Spink, 1995; Clemente et al., 2020; Osca and García-Salmones, 2010). Observational studies show an increase of players' participation and their actions efficacy in youth soccer players when there is a reduction of the number of players and field size (Escudero and Palao, 2005; Jara et al., 2018; Lapresa et al., 2006; Oppici et al., 2018; Ortega-Toro et al., 2018). These rules changes could contribute to a better environment to promote cooperation between players.

Some studies have shown GC and cohesion have relevant mutual relationships, despite that they are based on very different theoretical and practical suppositions (Olmedilla et al., 2011). Although cohesion is a group value, and sports cooperation is an individual value, their connections may mean that reductions in the field size and the number of players per team could lead to an increase in GC. For this reason, previous studies recommend that group cooperation should be encouraged, with the aim of achieving an improvement in prosocial behaviour, and a more educational and formative sport (Olmedilla et al., 2011). However, no study has analysed the relationship between the use of modified competition rules and GC. Therefore, the aim of this study was to analyse the effects of the modification of the pitch size, goal size, and the number of players per team on the level of cooperation in youth soccer players (U-12).

\section{Methods}

\section{Design}

A quasi-experimental study of type A-B-A was developed to assess the effect of rule changes in competition on player cooperation. In situation A (first and third tournament), the official rules by the Royal Spanish Soccer Federation for U-12 were used. In situation B (second tournament), a modification of official rules was used. This type of design is characterized by two untreated situations (first and third phase) and one 
experimental situation (second phase). The use of a third untreated situation (control mode) gives the study more internal validity than classic A-B type designs, which use a single control (Barlow and Hersen, 1973). The independent variable of the study was the competition format: official rules of the Royal Spanish Soccer Federation for U-12 or modified rules. The differences between the official competition and the modified competition were the following: size of the playing field ( $58 \times 38 \mathrm{~m}$ vs. $38 \times 20 \mathrm{~m}$ ); number of players per team on the field (8-a-side vs. 5 -aside); and goal size (6 2 $2 \mathrm{~m}$ vs. $3 \times 2 \mathrm{~m})$.

\section{Participants}

The sample was composed of 48 players from four U-12 soccer teams. The characteristics of the players were the following: age $(11.73 \pm 0.43$ years); training per week (3.27 \pm 0.65 hours), and playing experience $(2.93 \pm 1.15$ years). Parents of players or legal tutors were informed of the study, and they provided their informed consent in writing. The study was approved by the Ethics Committee of the principal author's research institution with an ID of 1944/2018.

\section{Variables}

The dependent variable was assessed through a "Sports Cooperation questionnaire" (García-Mas et al., 2006), which included 14 items related to conditional cooperation, situational cooperation with the coach, disposition to unconditional cooperation, situational cooperation with teammates, and situational cooperation outside the field of play, and specific questions about players' perception of cooperation. Four technical-tactical actions performed by players during the matches were registered: individual actions (no collective action), collective actions (e.g., give and go, cross over run, creation of free space, etc.), teammate supportive actions, and passes. The technicaltactical variables registered were part of the "Observation instrument for technical and tactical actions of the offensive phase in soccer" (OrtegaToro et al., 2019).

[INSERT TABLE 1. Description of the rules implemented in the tournaments (8-a-side and 5a-side)]

\section{Procedures}

Participants played a total of 24 matches; i.e., six matches in the first tournament (T1), 12 matches in the second tournament (T2), and six matches in the third tournament (T3). The three tournaments were played over a period of three weeks, after the competitive season. The tournaments were played on the weekend. All the tournaments were played at a similar time of day and under similar weather conditions. During the three tournaments, the same teams participated in a league system, in which they all played in a single round. In the first and the third tournament (situation A), matches were played under the official A-8 soccer rules established by the Royal Spanish Soccer Federation, except for playing time: two 20 -min periods. The playing time was changed to match the playing time of the modified tournament. In the second tournament (situation B), each team played the same matches as in the first and third tournaments, but each team was divided into two sub-teams. This subdivision allowed playing two simultaneous matches on adjacent soccer fields, with two 20min periods, played on a $38 \times 20 \mathrm{~m}$ soccer field (division of the field into 2 fields used in tournament $\mathrm{A}$ ), with five players plus one field player for substitutions, and two goals each of $3 x$ $2 \mathrm{~m}$. After the first simultaneous game between sub-teams of a team, the sub-teams that did not play together initially played each other. The result of the matches was calculated from the overall goals scored in both matches. It should be noted that throughout the tournament, coaches distributed the minutes played by each player equally, with a system of substitutions preestablished among the players of the same team.

\section{Measures}

The administration of the questionnaire was completed at the end of each of the three tournaments. The "Sports Cooperation Questionnaire" (García-Mas et al., 2006) was used to record the cooperation variables (Table 2). Fourteen closed questions composed the questionnaire with a 10-item Likert scale: four questions related to conditional cooperation, three questions related to situational cooperation with the coach, three questions related to disposition of unconditional cooperation, two questions related to situational cooperation with teammates, and two questions related to situational cooperation outside the field of play. One question of the disposition of unconditional cooperation included in the original questionnaire was not included in this study, since it was focused on cooperation in 
training. Along with each of the items in the questionnaire, in T2 and T3, players were asked whether they had experienced higher, equal or lower cooperation than in the previous tournament for the different factors. The questionnaire was filled individually by each player approximately 15-30 minutes after the last game of the tournament. In all the tournaments the same procedures were used and the questionnaire was explained and provided by the same researcher. The observations of these technical-tactical variables were done by trained observers (Master in Sports Science with at least five years of experience in match analysis and soccer) from the recording of the matches (elevated rear view). The reliability of the observers was measured before and after the observation. The lowest level of inter-observer reliability was 0.83 , and the lowest level of intraobserver reliability was 0.92 (Kappa index).

\section{Data analysis}

Data of the different cooperation variables are presented in the results section on a scale from 0 to 10 in order to compare the impact of the intervention on cooperation. To evaluate the possible differences between the three tournaments analysed, an analysis of variance with repeated measures was used. To this end, Mauchley's sphericity was used, from which it was decided to use the Pillai's trace or the assumed sphericity. For the post hoc analysis, the Bonferroni Post Hoc was used. All data were treated with a significance level of $p<.05$. To measure the magnitude of the effect size the eta square $\left(\eta^{2}\right)$ was used using the following classification (Ferguson, 2009): no effect $\left(\eta^{2}<0.04\right)$, minimal effect $\left(0.04 \leq \eta^{2}<0.25\right)$, moderate effect $\left(0.25 \leq \eta^{2}<0.64\right)$, and strong effect $\left(\eta^{2} \geq 0.64\right)$. The SPSS software version 24.0 was used for statistical analysis.

\section{Results}

Table 3 presents the descriptive values of the different cooperation variables in particular tournaments analysed. Conditional cooperation and situational cooperation outside the field of play had similar values between the tournaments analysed $\left(\mathrm{F}_{2,37}=2.342, p=.111, \eta^{2}=.121 ; \mathrm{F}_{2,37}=\right.$ $0.208, p=.813, \eta^{2}=.018$ ). For the situational cooperation values with the coach, the lowest values were found in T2. Statistically significant differences were observed $\left(\mathrm{F}_{2,37}=3.527, p=.041, \eta^{2}\right.$ $=.171)$ between $\mathrm{T} 1$ and T2 $(p=.048)$, as well as between T2 and T3 ( $p=.033)$. The values of the disposition of unconditional cooperation were significantly higher in T3 ( $\mathrm{F}_{2,37}=3.765, p=.033, \eta^{2}$ $=.181$ ). Significant differences were found between T1 and T3 $(p=.049)$, and between T2 and T3 ( $p=$ .048). The lowest value for the situational cooperation with teammates was recorded in $\mathrm{T} 2$. A tendency for statistical significance was found in this variable $\left(\mathrm{F}_{2,37}=3.201, p=.053, \eta^{2}=.158\right)$. Furthermore, a tendency to statistical significance was observed between T1 and T2 ( $p=.053)$.

Table 4 shows the percentage of responses in the perception of their levels of cooperation between the different tournaments. Most of the players perceived the same cooperation in tournaments 1 \& 3 in comparison with tournament 2 or higher cooperation in tournament 2. Two out of 10 players reported having experienced higher levels of conditioned cooperation in T2 than in T1 and T3. Analysing the situational cooperation with the coach, it was perceived higher in T2 for 3 out of 10 players compared with $\mathrm{T} 1$ and 1 out of 10 players compared with T3. On the average, between three and four out of 10 players found higher disposition of unconditional cooperation and the situational cooperation outside the field of play in T2. Furthermore, between three and four out of 10 players perceived higher situational cooperation with teammates in $\mathrm{T} 2$.

With regard to players' technical-tactical actions (Figure 1), a significantly higher number of individual actions $\left(\mathrm{F}_{2,35}=12.022, p=0.001, \eta^{2}=\right.$ $0.414)$, collective actions, supporting actions $\left(\mathrm{F}_{2,34}\right.$ $\left.=13.374, p=0.001, \eta^{2}=0.440\right)$, and passes $\left(\mathrm{F}_{2,35}=\right.$ 8.627, $p=0.001, \eta^{2}=0.330$ ), were found in the tournament with modified rules (T2). These differences had a moderate effect size and were not found between the second and the third tournament in the occurrence of passes. 
Table 1

Description of the rules implemented in the tournaments (8-a-side and 5-a-side).

\begin{tabular}{lcc}
\hline Rules & Official Rules (8-a-side) & Modified Rules (5-a-side) \\
\hline Number of players & 7 field players + 1 goalkeeper & 4 field players + 1 goalkeeper \\
Number of players (team) & 15 & 7 \\
Field size (m) & $58 \times 38 \mathrm{~m}$ & $38 \times 20 \mathrm{~m}$ \\
Goal size (m) & $6 \times 2 \mathrm{~m}$ & $3 \times 2 \mathrm{~m}$ \\
Penalty area size (m) & $24 \times 9 \mathrm{~m}$ & $12 \times 6 \mathrm{~m}$ \\
Goal area size (m) & $12 \times 3 \mathrm{~m}$ & None used \\
Ratio of $\mathrm{m}^{2}$ per field player & $314 \mathrm{~m}^{2}$ & $190 \mathrm{~m}^{2}$ \\
$\mathrm{~m}^{2}$ of the goal & $12 \mathrm{~m}^{2}$ & $6 \mathrm{~m}^{2}$ \\
Ball size (n) & 4 & 4 \\
Substitutions & Unlimited & Unlimited \\
Time (minutes) & $2 \times 20$ & $2 \times 20$ \\
\hline
\end{tabular}

\section{Table 2}

Sports Cooperation Questionnaire" (García-Mas et al., 2006).

Dispositional and conditional cooperation

1. When I help the coach, following her/his instructions and working hard in games and practices, I expect to receive recognition, to get put in the game, or for my coach to tell me.

2. When I help a teammate on the field through my efforts, I expect his/her recognition in some way.

3. My cooperation with my teammates and coach, both in games and in practices, depends on their collaboration with me.

4. If everyone works hard and we help each other, the team can go farther and better achieve their goals.

Situational cooperation with the coach

5. I work with the coach, whether I play on a regular basis or am a bench player.

6. I always follow the instructions of the coach, and I abide by her/his decisions, both in games and in practice, even if I have to sacrifice my game ideas.

7. I cooperate with the coach, whether I play on a regular basis or am a bench player.

Dispositional and unconditional cooperation

8. If everyone cooperates, the team is closer, and it can perform better and do better.

9. I cooperate during the game, even if it goes unnoticed, by moving without the ball and covering a teammate, for example.

11. I collaborate with my teammates and coach, no matter the game circumstances.

Situational cooperation with teammates

12. I collaborate with my teammates, even if they are more skillful than I am.

13. I collaborate with my teammates, even if there are some players in the team that do not help their teammates.

Situational Cooperation outside the field of play

14. To achieve our team goals we have to help one another off the field, with personal issues, or in the locker room.

15. It is just as important to cooperate off the field as it is in the game, although I consider myself a professional.

Legend: Question number 10 in the original questionnaire "

I work hard in practices even if this means competing against a teammate." was not included in this study. 
Table 3

Average and standard deviation of the group cooperation values in different tournaments (values expressed on a scale 0-10).

\begin{tabular}{lcccc}
\hline Cooperation & $\begin{array}{c}\mathrm{T} 1 \\
(8 \mathrm{v} 8)\end{array}$ & $\begin{array}{c}\mathrm{T} 2 \\
(5 \mathrm{v} 5)\end{array}$ & $\begin{array}{c}\mathrm{T} 3 \\
(8 \mathrm{v} 8)\end{array}$ & $\begin{array}{c}\text { Post } \\
\text { Hoc }\end{array}$ \\
\hline Conditional cooperation & $7.72 \pm 1.83$ & $7.50 \pm 1.94$ & $8.20 \pm 1.87$ & n.s. \\
Situational cooperation with the coach & $8.72 \pm 1.45$ & $8.23 \pm 1.30$ & $8.76 \pm 1.06$ & $\mathrm{~T} 1>\mathrm{T} 2<\mathrm{T} 3$ \\
Disposition of unconditional cooperation & $8.67 \pm 1.76$ & $8.55 \pm 1.33$ & $9.11 \pm 0.78$ & $\mathrm{~T} 1=\mathrm{T} 2<\mathrm{T} 3$ \\
Situational cooperation with teammates & $8.92 \pm 1.26$ & $8.11 \pm 2.19$ & $8.88 \pm 1.49$ & n.s. \\
Situational cooperation outside the field of play & $9.07 \pm 1.17$ & $8.92 \pm 1.26$ & $9.04 \pm 1.33$ & n.s. \\
\hline
\end{tabular}

Legend: T1 (8v8): Tournament 1 (8 a-side); T2 (5v5): Tournament 2 (5 a-side);

T3 (8v8): Tournament 3 (8 a-side); n.s = non-significant

Table 4

Evolution of the perception of group cooperation levels (differences expressed in percentages).

\begin{tabular}{|c|c|c|c|c|c|c|}
\hline \multirow{2}{*}{ Cooperation } & \multicolumn{3}{|c|}{$\begin{array}{l}\text { Differences between Tournaments } 1 \\
\qquad \& 2\end{array}$} & \multicolumn{3}{|c|}{$\begin{array}{l}\text { Differences between Tournaments } \\
\qquad 2 \& 3\end{array}$} \\
\hline & $\begin{array}{l}\text { Less than } \\
\text { T1 }\end{array}$ & Same as T1 & $\begin{array}{l}\text { More } \\
\text { than T1 }\end{array}$ & $\begin{array}{l}\text { Less than } \\
\text { T2 }\end{array}$ & Same as T2 & $\begin{array}{l}\text { More } \\
\text { than T2 }\end{array}$ \\
\hline Conditional cooperation & $2.4 \%$ & $73.1 \%$ & $24.3 \%$ & $0.0 \%$ & $81.25 \%$ & $18.75 \%$ \\
\hline $\begin{array}{l}\text { Disposition of unconditional } \\
\text { cooperation }\end{array}$ & $0.0 \%$ & $60.0 \%$ & $40.0 \%$ & $0.0 \%$ & $68.7 \%$ & $31.25 \%$ \\
\hline $\begin{array}{l}\text { Situational cooperation with } \\
\text { teammates }\end{array}$ & $0.0 \%$ & $65.0 \%$ & $35.0 \%$ & $0.0 \%$ & $59.3 \%$ & $40.6 \%$ \\
\hline $\begin{array}{l}\text { Situational cooperation outside the } \\
\text { field of play }\end{array}$ & $0.0 \%$ & $52.5 \%$ & $47.5 \%$ & $0.0 \%$ & $65.6 \%$ & $34.3 \%$ \\
\hline
\end{tabular}

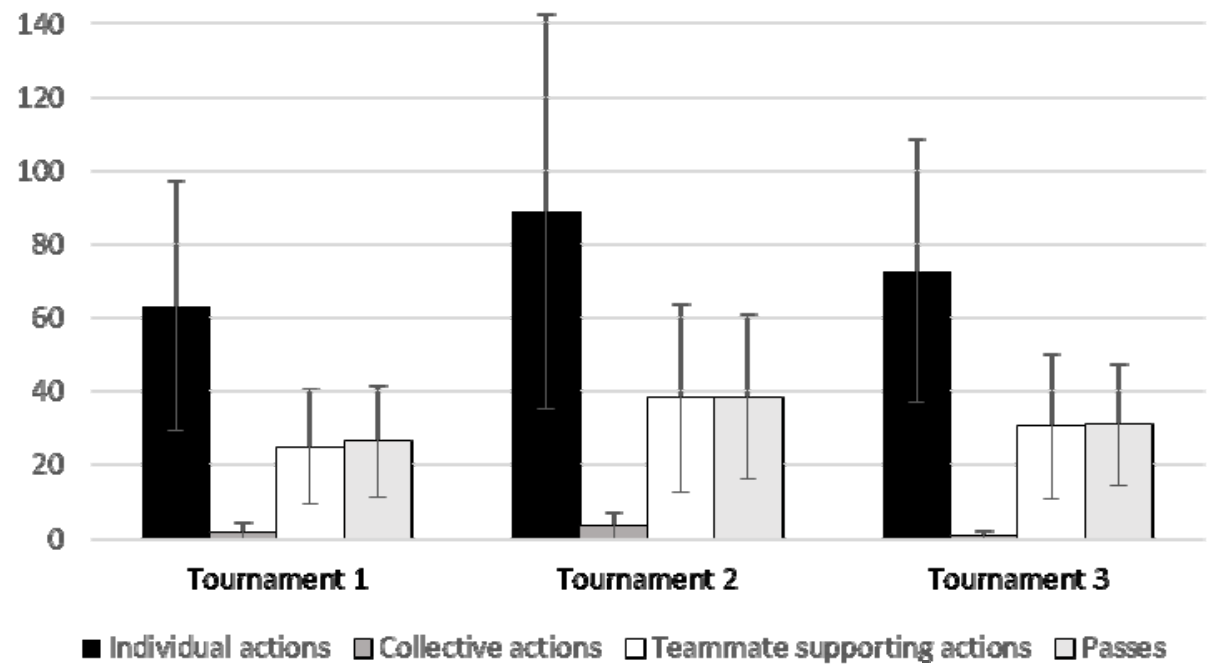

Figure 1

Technical-tactical actions performed by players in each tournament 


\section{Discussion}

This study aimed to analyse the effect of the modification of the pitch size, goal size, and the number of players in the teams on the level of cooperation in youth soccer players (U-12). This knowledge could help understand the impact of sport rules adaptations on cooperation. The findings of this study showed group cooperation was the same or there was a slight reduction with the modified rules (smaller field size, smaller goal, and fewer players). Players perceived that there was the same group cooperation in both competition formats. The proposed competition format involved more actions, passes, and teammate supportive actions. However, although the collective cooperation increased, the occurrence of this type of action was not sufficient to change players' perception of cooperation. Therefore, both competition formats involved similar group cooperation in U-12 players. It must be considered that this study evaluated the punctual effect of this rules change (one tournament). The cooperation values found in this population of U-12 male soccer players were significantly higher in three tournaments than the values found in senior male players of different sports (García-Mas et al., 2006; Lameiras et al., 2014). Numerous aspects can produce these differences, such as age, maturation, previous experience, or the level of competition. One must consider that previous studies assessed the cooperation in training and not during competition. Future studies are needed to understand how the group cooperation of players evolves through the season and the different stages of development.

The situational cooperation with the coach was lower in the tournament with the modified rules, although $60 \%$ of the players perceived the same situational cooperation with the coach in different tournaments. The reasoning for these findings may be related to the organization of this tournament with the modified rules. The reduction in players per team in the matches meant that the team was divided into two sub-teams that played against the opponent's sub-teams in order to maintain players' play time. Therefore, the coach had to instruct two teams at the same time. His/her attention and interaction with them was divided in the second tournament.
It should also be mentioned that in this tournament, teams played with a different tactical disposition and they could not get the normal instruction or feedback from their coaches. Previous studies showed players felt uncomfortable in situations where coaches used a system of rotation in competition, as they perceived a decrease in their coach's attention (Aguiar and Almeida, 2013). This discomfort may affect their goal orientation of the experience. Focusing more on the ego than on the task involved a reduction in the situational cooperation with the coach (Lameiras et al., 2014).

The values of the unconditioned dispositional cooperation were lower in the tournament with the modified rules, although $60 \%$ of the players perceived the same cooperation in different tournaments. The reasons for these results could be that the modified rules involved a new learning environment (GarcíaMas et al., 2006; Olmedilla et al., 2011). The new competition rules may involve different tactical disposition and technical situations to resolve. Previous observational studies showed that a reduction in the number of players and field size involved more variability in the actions performed by young players (Escudero and Palao, 2004; Lapresa et al., 2006). These new situations could affect the players' perceptions of how they cooperate due to the fact that players were more focused on resolving the game situations. Future studies should be conducted regarding the effect of the rules change on this factor of the sports cooperation when players have more experience with the proposed rules.

The conditional cooperation did not change between tournaments. Around $70-80 \%$ of the players perceived that this factor in their sports group cooperation was the same in different competition formats. At a similar level, no differences were found in the cooperation with teammates on and off the field between the different tournaments. Players presented high values of cooperation in all the tournaments. The modified rules or the structure of the tournament did not affect the cooperation between players. The maintenance of sports group cooperation in the new competitive approach did not affect other motivational constructions (Lameiras et al., 2014; Leo et al., 2009; 2011; Olmedilla et al., 2011). These results may be expected due to the fact that this 
factor of group cooperation is related to the players' cooperation characteristics. Another possible factor could be that the intervention was performed in a punctual action. Previous studies showed when the situation was competitive it did not influence how people dealt with it (Perry and Clough, 2017).

In summary, the results show that both competition rules involved similar values of cooperation. In two dimensions of the cooperation, the proposed rules presented lower levels of group cooperation (unconditional and situational cooperation with the coach). The causes of the lower values in these dimensions may be related to the organization of the experimental tournament (sub-division of the teams and use of the half of the previous field) and to the changes in the tactical disposition that involved the proposed rules (8-to-8 vs. 5-to-5). Regarding the limitations of the study, it should be noted that the studied sample had specific characteristics regarding age, performance level, and sport (U-12, male, and recreational level), and limited experience playing with these rules. The authors attempted to create quasi-experimental conditions that could be applicable to soccer organizations and federations. More studies are needed to verify these findings in this age group and other stages of the players' development. Future studies should analyse interaction of the cooperation with other psychological variables such as self-esteem or motivation, and the impact of the rules change on players' and coaches' actions and interactions.

\section{Acknowledgements}

This work was supported by Murcia Regional Soccer Association's (Spain) Soccer Project. Grant FFRMUMU-04 0092 321B 64502 14704; and Ministry of Economy, Industry and Competitiveness, under Grant DEP2017-90641-REDT.

\section{References}

Aguiar R, Almeida PL. With which coach are we practicing today? Leadership, cooperation, and perforamnce of a soccer coaches rotation system. Annu Clin Health Psychol, 2013; 9: 73-75

Almeida PL, Lameiras J, Martins S, Olmedilla A, Ortega E, García-Mas A. Evaluation of perception of sport cooperation: psychometric properties of the Portuguese version of the CCD. Lab psicol, 2013; 10(1): 3546

Balaguer I, Castillo I, Duda JL. Autonomy support, needs satisfaction, motivation and well-being in competitive athletes: a test of the Self-determination Theory. Rev Psicol Deporte, 2008; 17(1): 123-139

Barlow DH, Hersen M. Single-case experimental designs: Uses in applied clinical research. Arch Gen Psychiatry, 1973; 29(3): 319-325

Burton D, Gillham AD, Hammermeister J. Competitive Engineering: Structural Climate Modifications to Enhance Youth Athletes' Competitive Experience. Int J Sports Sci Coach, 2011; 6(2): 201-217

Buszard T, Reid M, Masters R. Farrow D. Scaling the equipment and play area in children's sport to improve motor skill acquisition: A systematic review. Sports Med, 2016; 46(6): 829-843

Carron AV, Spink KS. The Group Size-Cohesion relationship in Minimal Groups. Small Group Res, 1995; 26(1): 86-105

Chase MA, Ewing ME, Lirgg CD, George TR. The effects of equipment modification on children's self-i and basketball shooting performance. Res Q Exerc Sport, 1994; 65(2): 159-168

Chater N, Vlaev I, Grinberg M. A new consequence of Simpson's paradox: Stable cooperation in one-shot prisoner's dilemma from populations of individualistic learners. J Exp Psychol Gen, 2008; 137: 403-421. doi:10.1037/0096-3445.137.3.403

Clemente F, Sanches R, Moleiro C, Gomes M, Lima R. Technical Performance and Perceived Exertion Variations Between Small-Sided Basketball Games in Under-14 and Under-16 Competitive Levels. J Hum Kinet, 2020; 71(1): 179-189

Duda JL. Maximizing motivation in sport and physical education among children and adolescents: The case for greater task involvement. Quest, 1996; 48(3): 290-302 
Elliott S, Bevan N, Litchfield C. Parents, girls' and Australian football: a constructivist grounded theory for attracting and retaining participation. Qual Res Sport Exerc Heal, 2019; 00(00): 1-22

Escudero JM, Palao JM. Effect of game modality (7-a-side and 11-a-side) on the use of technical actions in youth sport (11-12 years). Lecturas: EF Deportes, 2004; 74

Farrow D, Reid M. The effect of equipment scaling on the skill acquisition of beginning tennis players. $J$ Sports Sci, 2010; 28(7): 723-732

Fehr E, Gintis H. Human motivation and social cooperation: Experimental and analytical foundations. Annu Rev Sociol, 2007; 33: 43-64

Ferguson CJ. An effect size primer: A guide for clinicians and researchers. Profess Psychol, 2009; 40(5): 532-538

García-Angulo A, García-Angulo FJ, Ortega E. Level of satisfaction and technical-tactical preferences of handball players in formative stages by gender of players. SPORT TK- Rev EuroAmericana Cienc Deporte, 2017; 6(2): 21-30

García-Angulo A, Ortega-Toro E, Giménez-Egido JM, García-Angulo FJ, Palao JM. Short-term effect of competition rule changes on collective effectiveness and self-efficacy in youth football players. Psychol Sport Exerc, 2020; 49: 101688

García-Mas A, Olmedilla A, Morilla M, Rivas C, García E, Ortega E. A new model of sportive cooperation and its evaluation by means a questionnaire. Psicothema, 2006; 18(3): 425-432

García-Mas A, Olmedilla A, Ortega E, Almeida P, Lameiras J, Sousa C, Cruz J. Cooperation and cohesion in competitive soccer teams. Int J Hisp Psychol, 2009; 2(1): 689-696

Gimenez-Egido JM, Ortega-Toro E, Palao JM, Verdú-Conesa I, Torres-Luque G. Effect of Modification Rules in Competition on Technical-Tactical Action in Young Tennis Players (Under-10). Front Psychol, 2020; 10: 2789

Jara D, Ortega E, Gómez MA, Sainz de Baranda P. Effect of Pitch Size on Technical-Tactical Actions of the Goalkeeper in Small-Sided Games. J Hum Kinet, 2018; 62(1): 157-166

Lameiras J, Almeida PL, García-Mas A. Relationships between cooperation and goal orientation among male professional and semi-professional team athletes. Percept Motor Skills, 2014; 119(3): 851-860

Lapresa D, Arana J, Garzón B. 9 football as an adjustment alternative to 11 football, based on the control of the space. Apunts. Educ Física Deportes, 2006; 4(86): 34-44

Leo FM, García Calvo T, Parejo I, Sánchez PA, García-Mas A. Application on an intervention program to improve cohesiveness and efficacy in basketball players. Cuadernos Psicol Deporte, 2009; 9(1): 73-84

Leo FM, Sánchez-Miguel PA, Sánchez-Oliva D, Amado D, García-Calvo T. Incidence of the cooperation, cohesion and collective efficacy on Incidence of the cooperation, cohesion and collective efficacy on performance in football teams. RICYDE. Rev Int Cienc Deporte, 2011; 7: 341-354

McEwan D, Zumbo BD, Eys MA, Beauchamp MR. The Development and Psychometric Properties of the Multidimensional Assessment of Teamwork in Sport. J Sport Exerc Psychol, 2018; 20: 1-13

Mccalpin ME, Evans M, Côté J. Young female soccer players' perceptions of their modified sport environment. Sport Psychol, 2017; 31(1): 65-77

McCarthy J, Bergholz L, Bartlett M. Re-designing Youth Sport: Change the Game, 2016; New York, NY: Routledge; 2016

Moon J. Achieving success through academic assertiveness: real life strategies for today's students. London: Routledge, 37-59; 2009

Olmedilla A, Ortega E, Almeida P, Lameiras J, Villalonga T, Sousa C, Torregrosa M, Cruz J, García-Mas A. Cohesion and Cooperation in sports teams. An Psicol, 2011; 27(1): 232-238

Oppici L, Panchuk D, Serpiello FR, Farrow D. The influence of a modified ball on transfer of passing skill in soccer. Psychol Sport Exerc, 2018; 39: 63-71

Ortega E, Palao JM, Sainz de Baranda P, García LM. Preferences and levels of satisfaction in technical and tactical actions and in type of ofense and defense utilized in competition by youth basketball players. Rev Psicol Deporte, 2009; 18(3): 343-348

Ortega-Toro E, García-Angulo A, Giménez-Egido JM, García-Angulo FJ, Palao, JM. Effect of modifications in rules in competition on participation of male youth goalkeepers in soccer. Int J Sports Sci Coach, 2018; 13(6): 1040-1047 
Ortega-Toro E, García-Angulo A, Giménez-Egido JM, García- Angulo FJ, Palao, JM. Design, Validation, and Reliability of an Observation Instrument for Technical and Tactical Actions of the Offense Phase in Soccer. Front Psychol, 2019; 10: 1-9

Osca A, García-Salmones L. The impact of size and diversity on group process and outputs. Psicothema, 2010; 22(1): 137-142

Perry JL, Clough PJ. Predicting cooperation in competitive conditions: The role of sportspersonship, moral competence, and emotional intelligence. Psychol Sport Exerc, 2017; 31: 88-92

Pons J, Ramis Y, García-Mas A, De la Llave AL, Pérez-Llantada MC. Perception of Competitive Anxiety in relation to Cooperation Level and Sport Commitment upon Formative Basketball Players. Cuadernos Psicol Deporte, 2016; 16(3): 45-54

Renshaw I, Oldham AR, Bawden M. Nonlinear Pedagogy Underpins Intrinsic Motivation in Sports Coaching. Open Sports Sci J, 2012; 5: 88-99

Scott-Ladd B, Chan CC. Using action research to teach students to manage team learning and improve teamwork satisfaction. Active Learn High Educ, 2008; 9(3): 231-248

Thomas GL, Wilson MR. Playing by the Rules: A Developmentally Appropriate Introduction to Rugby Union. Int J Sports Sci Coach, 2015; 10(2-3): 413-423

Timmerman E, De Water J, Kachel K, Reid M, Farrow D, Savelsbergh G. The effect of equipment scaling on children's sport performance: the case for tennis. J Sports Sci, 2015; 33(10): 1093-1100

Yang Z, Li T, Zheng Y. Understanding cooperation in a single-trial prisoner's dilemma game: Interactions among three conditions. Soc Behav Pers, 2013; 41: 721-730

\section{Corresponding author:}

\section{Enrique Ortega-Toro}

Faculty of Sport of Science - University of Murcia

Argentina St. s/n

Campus de San Javier

30720 - Santiago de la Ribera-San Javier, Murcia, Spain.

Tel: +34 868888824

Fax: +34 868888672

E-mail address: eortega@um.es 